\title{
Can we explain the dynamics of the UK FTSE 100 stock and stock index futures markets?
}

Article

Accepted Version

Brooks, C. and Garrett, I. (2002) Can we explain the dynamics of the UK FTSE 100 stock and stock index futures markets? Applied Financial Economics, 12 (1). pp. 25-31. ISSN 14664305 doi: https://doi.org/10.1080/09603100110087996 Available at https://centaur.reading.ac.uk/24155/

It is advisable to refer to the publisher's version if you intend to cite from the work. See Guidance on citing.

To link to this article DOI: http://dx.doi.org/10.1080/09603100110087996

Publisher: Taylor \& Francis

All outputs in CentAUR are protected by Intellectual Property Rights law, including copyright law. Copyright and IPR is retained by the creators or other copyright holders. Terms and conditions for use of this material are defined in the End User Agreement.

www.reading.ac.uk/centaur

\section{CentAUR}


Central Archive at the University of Reading

Reading's research outputs online 
This is an Author's Accepted Manuscript of an article published in Applied Financial Economics (2002) [copyright Taylor \& Francis], available online at: http://www.tandfonline.com/10.1080/09603100110087996. 


\title{
Can We Explain the Dynamics of the UK FTSE 100 Stock and Stock Index Futures Markets?
}

\author{
Chris Brooks \\ and \\ Ian Garrett
}

\begin{abstract}
If stock and stock index futures markets are functioning properly price movements in these markets should best be described by a first order vector error correction model with the error correction term being the price differential between the two markets (the basis). Recent evidence suggests that there are more dynamics present than should be in effectively functioning markets. Using self-exciting threshold autoregressive (SETAR) models we analyse whether such dynamics can be related to different regimes within which the basis can fluctuate in a predictable manner without triggering arbitrage. Our findings reveal that the basis shows strong evidence of autoregressive behaviour when its value is between the two thresholds but that the extra dynamics disappear once the basis moves above the upper threshold and their persistence is reduced, although not eradicated, once the basis moves below the lower threshold. This suggests that once nonlinearity associated with transactions costs is accounted for, stock and stock index futures markets function more effectively than is suggested by linear models of the pricing relationship.
\end{abstract}

Keywords: $\quad$ stock index, stock index futures, arbitrage, basis, error correction, nonlinearity, threshold, regime, SETAR models.

* ISMA Centre, Department of Economics, University of Reading, Whiteknights, Reading RG6 6AA, United Kingdom, and Department of Accounting and Finance, University of Manchester, 
Manchester M13 9PL, United Kingdom respectively. 


\section{Can We Explain the Dynamics of the UK FTSE 100 Stock and Stock Index Futures Markets?}

\section{Introduction}

Following the 1987 stock market crash, concern has been expressed (see, for example, the Brady Commission Report (1988)) about whether derivative markets, particularly stock index futures markets, and underlying stock markets function effectively, that is, whether they function as one entity such that to all intents and purposes they are indistinguishable. ${ }^{1}$ Antoniou and Garrett (1995) use the notion that these markets should be indistinguishable to arrive at a framework which allows appraisal of whether stock and stock index futures markets function as one. They argue that if these markets are indistinguishable the only factor, apart from news, that should move prices in both markets is arbitrage with the result that since the same common factor is driving price movements in both markets it should not be possible to tell them apart empirically. If this is the case then the relationship between stock and stock index futures markets should be best described by a restricted vector error correction model (VECM) where the error correction term is the relative stock-futures price differential (the basis) which in turn is closely related to arbitrage, the factor that ensures these two markets remain closely linked. If the first order VECM is appropriate then it is not possible to identify structural equations for returns in stock and stock index futures markets and the two markets are indeed indistinguishable empirically.

\footnotetext{
${ }^{1}$ Not surprisingly, the evidence suggests that links between stock and stock index futures markets broke down during the October 1987 crash. See Harris (1989) and Kleidon and Whaley (1992) for evidence relating to the US and Antoniou and Garrett (1993) for evidence relating to the UK.
} 
Using daily data on the FTSE 100 Index and Index Futures contract Antoniou and Garrett (1995) find that the basis up to three trading days prior carries predictive power for movements in the FTSE 100 Index, suggesting that the stock market in the UK is ineffectively functioning and the possible existence of unexploited arbitrage opportunities. In this paper we analyse whether such dynamics can be explained as the result of different regimes within which arbitrage is not triggered and outside of which arbitrage will occur. The rationale for the existence of different regimes in this context is that the basis (adjusted for carrying costs if necessary), which is very important in the arbitrage process, can fluctuate within bounds determined by transaction costs without actually triggering arbitrage. Hence an autoregressive relationship between the current and previous values of the basis could arise and persist over time within the threshold boundaries since it is not profitable for traders to exploit this apparent arbitrage opportunity. Hence there will be thresholds within which there will be no arbitrage activity but once these thresholds are crossed, arbitrage should drive the basis back within the transaction cost bounds. If markets are functioning effectively then irrespective of the dynamics of the basis within the thresholds, once the thresholds have been crossed the additional dynamics should disappear.

The rest of the paper is organised as follows. In section 2, we briefly review the issue of effectively functioning markets and the question of whether stock and stock index futures markets function as one. In section 3, we turn our attention to the modelling of stock-stock index futures dynamics using self-exciting threshold autoregressive (SETAR) models which extend the linear framework to allow for the existence of different regimes alluded to earlier. Section 4 offers some concluding remarks. 


\section{Effectively Functioning Markets And The Pricing Relationship Between Stock And Stock Index Futures Markets}

One of the concerns expressed by the Presidential Task Force Report (1988) following the 1987 stock market crash was the extent to which stock and stock index futures markets function as if they are one, something which they should do if they are functioning effectively. A framework that allows analysis of this issue is touched upon in Antoniou and Garrett (1993) and developed more fully in Antoniou and Garrett (1995). The framework arises by unifying two strands of the literature on pricing relationships between stock and stock index futures markets. To date, empirical research has focused either on lead-lag relationships between the two markets (see, for example, Kawaller, Koch and Koch (1987) and Chan (1992)) or the behaviour of mispricing and the availability of arbitrage opportunities (see, for example, Yadav and Pope (1990) and Chung (1991)). Lead-lag relationships are concerned with whether the futures market leads the spot market, whether the spot market leads the futures market or whether bi-directional feedback exists and as such are essentially causality tests in the spirit of Granger (1969) and Sims (1972). Tests of mispricing are typically concerned with identifying whether there are profitable arbitrage opportunities arising as a result of stock and stock index futures prices moving out of line with each other. Identification of such opportunities is based on the theoretical relationship between the stock index futures price and the underlying stock index portfolio. This relationship is given by (MacKinlay and Ramaswamy (1988), Stoll and Whaley (1990))

$$
F_{t}^{*}=S_{t} e^{(r-d)(T-t)}
$$

or 


$$
f_{t}-s_{t}=(r-d)(T-t)
$$

where $f_{t}^{*} 3$ is the natural $\log$ of the fair or theoretically correct stock index futures price quoted at time $t, s_{t} 4$ is the natural $\log$ of the value of the underlying stock index, $r$ is a risk-free rate of interest, $d$ is the yield on dividends derived from the stock index until the futures contract matures and $(T-t) 5$ is the time to maturity of the futures contract. The existence of arbitrage opportunities is determined by comparing the actual futures price ${ }^{f_{t}} 6$ with the fair futures price $f_{t}^{*} 7$ since, if the futures contract is priced correctly, $f_{t}-f_{t}^{*}=08$ where again lowercase letters denote variables in natural logarithmic form. Any deviation of this theoretical basis ${ }^{2}$ from the equality is compared with transactions costs to determine if arbitrage opportunities are available. Miller, Muthuswamy and Whaley (1994) actually go further than this and argue that since stocks go ex-dividend overnight and since interest is not paid if the underlying portfolio is bought and sold within a day, the effects of the cost of carry on the basis can be nullified. Therefore, as long as opening prices are not used, dividend and interest effects will have no influence on the basis. Thus, the right hand side of (2) becomes zero and the theoretical and simple basis become the same. If these two strands of the literature are then brought together, the resultant model of the pricing relationship between stock and stock index futures markets is a vector error correction model (VECM) of the form

\footnotetext{
${ }^{2}$ One must be careful when talking about the basis for there are several definitions. We will refer to the $(\log )$ futures to $(\log )$ fair price differential as the theoretical basis. We will refer to the $(\log )$ futures to $(\log )$ cash price differential as the basis. Where there is risk of confusion, we will refer to the latter as the simple basis.
} 


$$
\Delta y_{\mathrm{t}}=\mu+\Gamma_{1} \Delta y_{\mathrm{t}-1}+\ldots+\Gamma_{\mathrm{k}-1} \Delta y_{\mathrm{t}-\mathrm{k}+1}-\Pi \mathbf{y}_{\mathrm{t}-1}+e_{\mathrm{t}}
$$

where $\Delta y=\left[\Delta f_{t}: \Delta s_{t}\right]$ and the term involving $\boldsymbol{y}_{-1}$ is the error correction term which from the discussion earlier is the basis. The final step in the framework for determining whether stock and stock index futures markets function effectively, that is, function as one, comes from the imposition of restrictions on (3). Intuitively, if stock and stock index futures markets are functioning as if they are one market they should react instantaneously to relevant information. This implies that in (3), the $\Gamma_{i}$ should be zero. However, should prices in the two markets drift too far apart arbitrage should drive them back into line. Since the basis gives an indication of whether arbitrage opportunities are present and since arbitrage involves the simultaneous purchase of one asset and sale of the other it is the basis that should drive price movements in both markets. If this is the case, then the markets depend only upon the same common factor, the basis, and should therefore effectively be indistinguishable in which case they can be said to function as one. This means that when both markets function as one, (3) collapses to

$$
\Delta y_{\mathrm{t}}=\mu+\Pi \mathbf{y}_{\mathrm{t}-1}+e_{\mathrm{t}}
$$

or

$$
\left[\begin{array}{c}
\Delta f_{t} \\
\Delta s_{t}
\end{array}\right]=\left[\begin{array}{l}
\pi_{11} \\
\pi_{21}
\end{array}\right]\left[f_{t-1}-s_{t-1}\right]+\left[\begin{array}{l}
u_{1 t} \\
u_{2 t}
\end{array}\right]
$$

This model captures the notion that the two markets function as one since examination of (5) reveals that a structural version of the model cannot be identified because they only differ by normalisation and hence the two markets are indistinguishable since they both depend only upon 
the same common factor, which is the arbitrage link (the basis) expected to keep the two prices in line.

Antoniou and Garrett (1995) use this framework to analyse the pricing relationship between the FTSE 100 Stock Index and Stock Index Futures contract in the UK. They use daily data over the period January 1985 to October 1992, splitting the sample into pre- and post-crash ones to determine if the crash had any lasting impact on the pricing relationship. They find that for both the pre- and post-crash samples, the returns on the FTSE 100 stock index futures contract are a function of the previous days basis only. However, for the stock market three lags of the basis carry explanatory power for returns on the FTSE 100 Stock Index. ${ }^{3}$ In the context of the framework discussed above, these results suggest that whilst the stock index futures market functions effectively the stock market does not, suggesting that stock returns are predictable. However, there is another possible explanation of such a finding in the context of nonlinear threshold models of the pricing relationship. We investigate whether these findings can be explained in the context of such a model in the next section.

\section{Threshold Models And The Relationship Between Stock and Stock Index Futures Prices}

Threshold autoregressive (TAR) models were first introduced by Tong (see Tong and Lim (1980), Tong (1983) and Tong (1990)). These models represent a natural extension of standard autoregressive models to the case where the parameters of the model are dependent upon the underlying variable being in different regimes. In general, the TAR model can be expressed as 


$$
y_{t}=\sum_{j=1}^{J} I_{t}^{(j)}\left(\phi_{0}^{(j)}+\sum_{i=1}^{p_{j}} \phi_{i}^{(j)} y_{t-i}+\varepsilon_{t}^{(j)}\right), \quad r_{j-1} \leq z_{t-d}<r_{j}
$$

where $I_{t}^{(j)} 13$ is an indicator function for the $j$ th regime, taking the value one if the underlying variable is in regime $j$ and zero otherwise, ${ }^{r}{ }_{j} 14$ is a threshold, $z_{t-d} 15$ is an observed variable determining the switching point between regimes, $d$ is known as the delay parameter and $\varepsilon_{t}^{(j)} 16$ is a zero mean IID error process. If the regime changes in this model are driven by lags of the dependent variable itself, that is $z_{t-d}=y_{t-d} 17$, then the model is a self-exciting (SE)TAR model.

The role of TAR models in analysing the pricing relationship between stock and stock index futures markets has received some attention for the S\&P 500 in the US (Yadav, Pope and Paudyal (1994) and Dwyer, Locke and Yu (1996)). To motivate their use, note that we can rewrite the pricing relationship (5) as a model of basis dynamics by subtracting $\Delta s_{t}$ from $\Delta f_{t}$ in (5) and writing the resultant model in terms of the basis $\left(b_{t}=f_{t}-s_{t}\right)$ :

$$
b_{t}=\alpha b_{t-1}+\varepsilon_{t}
$$

where $\alpha=\left(1-\gamma_{12}-\gamma_{21}\right)$ and $0<\alpha<1$ if the system is stable which it must be if both of the markets function as one entity. The argument for the presence of thresholds in the pricing relationship is then based on arbitrage opportunities arising when the basis moves outside of noarbitrage boundaries which exist in the presence of transaction costs. In the absence of

\footnotetext{
${ }^{3}$ Note that these results suggest that the basis itself follows an AR(3) process.
} 
transaction costs, deviations of the basis away from zero in either direction will trigger arbitrage. The existence of transaction costs, however, mean that the basis can deviate from zero without actually triggering arbitrage. Thus, assuming that there are no differential transaction costs, there will be upper and lower bounds within which the basis can fluctuate without triggering arbitrage. This suggests that profitable arbitrage opportunities will not be present when $r_{0} \leq b_{t-1}<r_{1} 19^{4}$ where $r_{0} 20$ and $r_{12}$ are the thresholds which determine which regime the basis is in. If these thresholds are interpreted as transaction cost bounds then when the basis falls below the lower threshold $\left(r_{0} 22\right)$ the appropriate arbitrage transaction is to buy futures and short stock. This applies in reverse when the basis rises above ${ }^{r_{1}} 23$. When the basis lies within the thresholds, there should be no arbitrage transactions. The question that is of interest here is whether the dynamics identified by Antoniou and Garrett (1995) persist once the basis is outside of the thresholds. This question is clearly of interest since if the dynamics persist outside of the thresholds, arbitrage is not working effectively in that arbitrage opportunities will persist. However, if the additional dynamics disappear outside of the threshold then there is little cause for concern since it implies that arbitrage opportunities do not overly persist and are being exploited if they are profitable net of transactions costs, which is as we would expect in effectively functioning markets. Whether this is the case is the subject matter of the next section.

${ }^{4}$ The fact that $r_{0} \leq b_{t-1} \leq r_{l}$ Error! Main Document Only. means that the delay parameter $d$ in (6) is set equal to 1 . The reason for setting the delay parameter equal to 1 comes from equations (4) and (5) which show that current movements in stock and stock index futures prices, and hence basis movements, are determined by the previous period's basis when they are effectively functioning. Kräger and Kugler (1993) also argue that the delay parameter should equal one since it is the previous period's observation that should determine the current state rather than observations further back in time. 


\section{A. Estimation, Data and Results}

While the SETAR model is autoregressive within each of the regimes, estimation of the parameter vector $\theta^{\prime}=\left(\phi_{i}, r_{j}, d, p_{j}\right) 24$ is considerably more complex than for a standard autoregressive process. The problem is that in general, the parameters cannot be determined simultaneously and as such the values of one parameter are likely to influence estimates of the others. Tong $(1983,1990)$ suggests a complex nonparametric lag regression procedure to estimate the values of the thresholds, $r$, and the delay parameter $d$. The autoregressive coefficients can then be estimated by nonlinear least squares (NLS) ${ }^{5}$ and the order of the piecewise linear components $p$ by some information criterion such as Akaike's. Whilst it is preferable to endogenously estimate the thresholds analytically as part of the optimisation procedure, the fact that the underlying relationship between the variables of interest is discontinuous in the thresholds makes this infeasible. Therefore, the only method available for estimating the thresholds in this manner is to optimise and evaluate the function with respect to the other parameters for every feasible value of the thresholds. We implement this procedure here by using a grid search procedure based on the quantiles of the distribution of returns. The value of the threshold selected is that which minimises the residual sum of squares. As previously argued, the basis lagged one period is chosen as the state-determining variable and we estimate two thresholds since these should correspond to the upper and lower boundaries within which the

\footnotetext{
${ }^{5}$ It is also possible to estimate the parameters by maximum likelihood (see Subba Rao and Gabr (1980)). Estimating the model used here by ML gives very similar parameter estimates to those given by using NLS. However, estimation by ML proved to be computationally much slower so we only discuss the results from estimation by NLS.
} 
basis can fluctuate without causing arbitrage. We also use three lags of the basis in each of the regimes in order to facilitate comparison with the results of the linear model estimated here and suggested by Antoniou and Garrett (1995).

The data we use are daily closing prices for the FTSE 100 Stock Index and FTSE 100 Stock Index Futures contract over the period January 1985 to October 1992. The futures series is a continuous one constructed by rolling over into the next contract in the month prior to expiration. The basis is then calculated as the difference between the log futures and log spot prices. The basis is plotted in figure 1 and table 1 contains some descriptive statistics for the basis over the whole sample period and the pre- and post-crash sample periods. ${ }^{6}$ The graph shows that for the vast majority of the sample period the basis is positive which in turn suggests that we should expect positive estimates of the thresholds. Table 2 reports results from estimating a linear AR(3) model for the basis. The results using the whole sample lend support to the conclusion that stock and stock index futures markets do not function as one on a daily basis, at least as far as the UK is concerned. Further, this result is not driven by extreme observations during the crash, as demonstrated by the results from the pre- and post-crash samples. To summarise this far, then, the results from the linear specification very strongly suggest that the stock and stock index futures markets in the UK do not function effectively as one entity since there is a highly significant autoregressive relationship in the basis.

Once we allow for threshold nonlinearity in the specification of the model, however, a very

\footnotetext{
${ }^{6}$ The pre-crash period is from January 1985 to October 1987 and the post-crash period is from October 1988 to the end of the sample.
} 
different picture emerges. Recall that in the presence of transaction costs the basis can fluctuate within boundaries without actually triggering arbitrage. Therefore, as long as the basis is within the thresholds, the dynamics of the basis are of little concern. However, should the basis cross the thresholds, arbitrage should ensure that any additional dynamics disappear. Irrespective of the sample period used, it can be seen from table 3, which gives the results of estimating a SETAR model with 2 thresholds ${ }^{7}$, that this is precisely what occurs here when the basis crosses the upper threshold: once the upper threshold is crossed, the basis follows an AR(1) process which is as it should if stock and stock index futures markets function as one entity. When the basis crosses the lower threshold, however, additional dynamics are still present although they are not nearly as pronounced as in the linear model. In terms of interpretation, when the basis crosses the upper threshold, this implies that the futures is overvalued and thus the appropriate strategy would be to short futures and go long in stock. The results suggest that when this is the case, both the stock and stock index futures markets effectively function as one entity. When the basis crosses the lower threshold, the appropriate strategy is to go long in the futures and short stock. Clearly, when this is the appropriate strategy to follow, the stock and stock index futures markets do not function effectively as one Our results also show that forcing the basis data to be drawn from a single regime as one would if one specifies a linear model, would represent an inappropriate restriction and a mis-specification, since the behaviour of the basis is different between the regimes. Specifically, the speed of adjustment is apparently quicker outside of the

\footnotetext{
${ }^{7}$ We began by estimating the model with three thresholds over the whole sample to allow for differential thresholds which reflect the differential transaction costs that different classes of arbitrageur face (see, for example, Yadav, Pope and Paudyal (1994)). However, there was little to distinguish between the second and third thresholds, estimates of the thresholds being 0.0104 , 0.0142 and 0.0158 , suggesting that the third threshold is spurious. Given this result, we reduced the number of thresholds to two, giving three regimes.
} 
threshold as traders can profitably react to correct mis-pricings.

\section{Conclusions}

In this paper we have investigated the role of self-exciting threshold autoregressive models in explaining the daily dynamics of the FTSE 100 index-index futures basis. If stock and stock index futures markets are functioning as if they are one entity, which they should if they are functioning effectively, then basis dynamics should be best described by an AR(1) process. Contrary to this prediction, the daily FTSE 100 index-index futures basis appears to be best described as an $\mathrm{AR}(3)$ process when a linear autoregressive model is used, suggesting that these markets do not function effectively as one entity. However, once allowance is made for the fact that the basis can fluctuate within bounds within which no arbitrage takes place, a very different picture emerges. When the basis crosses the upper threshold, the additional dynamics disappear, suggesting that both markets function effectively. Note that this scenario corresponds to the case where the futures contract is overvalued and the appropriate arbitrage strategy is to short futures and go long in stock. When the basis crosses the lower threshold, however, the additional dynamics do not disappear completely, suggesting that when the appropriate strategy is to short stock and go long in futures the FTSE 100 stock and stock index futures markets do not appear to function effectively as one entity. One possible explanation of this finding is that restrictions on the short selling of stock prevent full adjustment taking place, leading to delayed adjustment. This problem does not arise when the basis crosses the upper threshold since there are few if any short sales restrictions in the stock index futures market, and the transactions costs of entering a short futures position should be lower than those of entering a short stock position. 
Thus our findings suggest that the source of ineffectiveness is the stock market. 


\section{References}

Antoniou, A. and I. Garrett, 1993. To what extent did stock index futures contribute to the October 1987 stock market crash?, The Economic Journal 103, 1444-1461.

Antoniou, A. and I. Garrett, 1995. Are stock and stock index futures markets effectively functioning?, mimeo, Brunel University.

Harris, L.H., 1989. The October 1987 S\&P 500 stock-futures basis, Journal of Finance 44, 7799.

Kleidon, A.W. and R.E. Whaley, 1992. One market ? Stocks, futures and options during October 1987, Journal of Finance 47, 851-877.

Kräger, H. and P. Kugler, 1993. Nonlinearities in foreign exchange markets: a different perspective, Journal of International Money and Finance 12, 195-208.

MacKinlay, A.C. and K. Ramaswamy, 1988. Index-futures arbitrage and the behaviour of stock index futures prices, Review of Financial Studies 1, 137-158.

Presidential Task Force, 1988. Presidential Task Force Report on Market Mechanisms. Submitted to the President, the Secretary of the Treasury and the Chairman of the Federal Reserve Board, January 1988.

Stoll, H.R. and R.E. Whaley, 1990. The dynamics of stock index and stock index futures returns, Journal of Financial and Quantitative Analysis 25, 441-468.

Subba Rao, T. and M.N. Gabr, 1980. A test for linearity of stationary time series, Journal of Time Series Analysis 1, 145-148.

Tong, H., 1983. Threshold Models in Nonlinear Time Series Analysis, Springer-Verlag: New York.

Tong, H., 1990. Nonlinear Time Series: A Dynamical Systems Approach, Oxford University Press.

Tong, H. and K.S. Lim, 1980. Threshold autoregression, limit cycles and cyclical data, Journal of the Royal Statistical Society B 42, 245-292.

Yadav, P.K., P.F. Pope and K. Paudyal, 1994. Threshold autoregressive modelling in finance : the price difference of equivalent assets, Mathematical Finance 4, 205-221. 


\section{Figure 1}

The Daily FTSE 100 Basis, January 1985 - October 1992

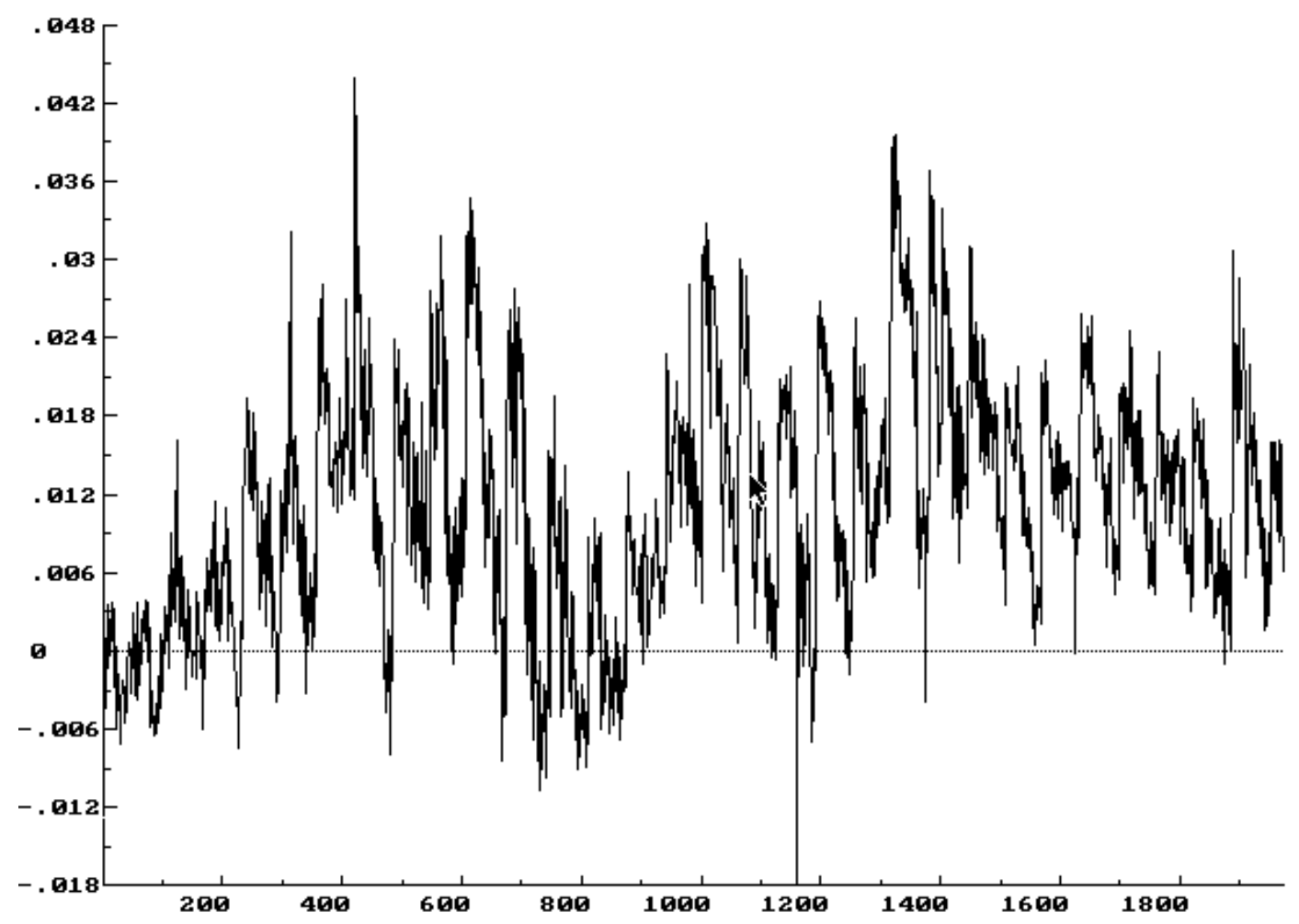

Table 1

Descriptive Statistics For The FTSE 100 Basis

\begin{tabular}{||l|c|c|c||}
\hline & Whole Sample & Pre-crash Sample & Post-crash Sample \\
\hline Mean & 0.011233 & 0.009370 & 0.014496 \\
Standard Deviation & 0.009215 & 0.009423 & 0.007911 \\
Skewness & 0.230204 & 0.511836 & 0.280079 \\
Excess Kurtosis & -0.257707 & -0.295789 & 0.186309 \\
Minimum & -0.017909 & -0.008409 & -0.017909 \\
Maximum & 0.043815 & 0.043815 & 0.039573 \\
ADF Unit Root Test & $-7.1761^{* *}$ & $-4.1020^{* *}$ & $-6.2694^{* *}$ \\
\hline \hline
\end{tabular}

Notes

** denotes rejection of the null of a unit root against the stationary alternative at $1 \%$ 
Table 2

Significance Of Basis Dynamics For The Linear Model

$b_{\mathrm{t}}=\phi_{0}+\phi_{1} b_{\mathrm{t}-1}+\phi_{2} b_{\mathrm{t}-2}+\phi_{3} b_{\mathrm{t}-3}+\varepsilon_{\mathrm{t}}$

\begin{tabular}{||c|c|c|c|}
\hline Parameter & Whole Sample & Pre-crash Sample & Post-crash Sample \\
\hline$\phi_{1} 25$ & $\begin{array}{l}0.7051^{* *} \\
(0.0225)\end{array}$ & $\begin{array}{l}0.7174^{* *} \\
(0.0377)\end{array}$ & $\begin{array}{l}0.6791^{* *} \\
(0.0315)\end{array}$ \\
& $0.1268^{* *}$ & $0.0946^{*}$ & $0.1650^{* *}$ \\
$\phi_{2} 26$ & $(0.0274)$ & $(0.0463)$ & $(0.0378)$ \\
& & & \\
$\phi_{327}$ & $0.0872^{* *}$ & $0.1106^{* *}$ & 0.0421 \\
& $(0.0225)$ & $(0.0377)$ & $(0.0315)$ \\
$\sigma_{\varepsilon} x 10_{28}^{3}$ & 4.0853 & 4.1015 & 4.0651 \\
\hline
\end{tabular}

Notes

${ }^{*}$ and ${ }^{* *}$ denote significance at the $5 \%$ and $1 \%$ levels 


\section{Table 3}

\section{Significance Of Basis Dynamics For The SETAR}

$$
\begin{gathered}
\text { Model With Two Thresholds } \\
\phi_{0}^{1}+\sum_{i=1}^{3} \phi_{i}^{1} b_{t-i}+\varepsilon_{t}^{1} \text { if } b_{t-1}<r_{0} \\
b_{t}=\phi_{0}^{2}+\sum_{i=1}^{3} \phi_{i}^{2} b_{t-i}+\varepsilon_{t}^{2} \text { if } r_{0} \leq b_{t-1}<r_{1} \\
\phi_{0}^{3}+\sum_{i=1}^{3} \phi_{i}^{3} b_{t-i}+\varepsilon_{t}^{3} \text { if } b_{t-1} \geq r_{1}
\end{gathered}
$$

\begin{tabular}{|c|c|c|c|c|c|c|c|c|c|}
\hline & \multicolumn{3}{|c|}{ Whole Sample } & \multicolumn{3}{|c|}{ Pre-crash Sample } & \multicolumn{3}{|c|}{ Post-crash Sample } \\
\hline & $b_{t-1} \underset{30}{<} r_{0}$ & $r_{0} \leq b_{t-1}<r$ & $b_{t-1} \geq r_{13}$ & $b_{t-1}<r_{32}$ & $\leq b_{t-1}<$ & $b_{t-1} \geq r_{133}$ & $\begin{array}{c}b_{t-1}<r_{0} \\
4\end{array}$ & $\leq b_{t-1}<r_{l}$ & $b_{t-1} \geq r_{13}$ \\
\hline$\phi_{136}$ & $\begin{array}{l}0.5743^{* *} \\
(0.0415)\end{array}$ & $\begin{array}{l}-0.6395 \\
(0.7549)\end{array}$ & $\begin{array}{l}0.8380^{* * *} \\
(0.0512)\end{array}$ & $\begin{array}{l}0.4745^{* *} \\
(0.0808)\end{array}$ & $\begin{array}{l}0.4482^{*} \\
(0.1821)\end{array}$ & $\begin{array}{l}0.8536^{* * *} \\
(0.0720)\end{array}$ & $\begin{array}{l}0.5019^{* * *} \\
(0.1230)\end{array}$ & $\begin{array}{l}0.7474^{* * *} \\
(0.1201)\end{array}$ & $\begin{array}{l}0.8397^{* * *} \\
(0.0533)\end{array}$ \\
\hline$\phi_{237}$ & $\begin{array}{l}0.2088^{* * *} \\
(0.0401)\end{array}$ & $\begin{array}{l}-0.0594 \\
(0.0846)\end{array}$ & $\begin{array}{c}0.0439 \\
(0.0462)\end{array}$ & $\begin{array}{l}0.2164^{* * *} \\
(0.0781)\end{array}$ & $\begin{array}{l}0.2608^{* * *} \\
(0.0950)\end{array}$ & $\begin{array}{l}-0.0388 \\
(0.0710)\end{array}$ & $\begin{array}{c}0.2011^{*} \\
(0.0874)\end{array}$ & $\begin{array}{l}0.2984^{* * *} \\
(0.0691)\end{array}$ & $\begin{array}{c}0.0689 \\
(0.0514)\end{array}$ \\
\hline$\phi_{338}$ & $\begin{array}{l}0.1330^{* *} \\
(0.0355)\end{array}$ & $\begin{array}{l}0.2267^{* *} \\
(0.0811)\end{array}$ & $\begin{array}{c}0.0415 \\
(0.0344)\end{array}$ & $\begin{array}{c}0.1142 \\
(0.0706)\end{array}$ & $\begin{array}{l}0.2309^{* *} \\
(0.0834)\end{array}$ & $\begin{array}{c}0.0770 \\
(0.0531)\end{array}$ & $\begin{array}{c}0.0434 \\
(0.0748)\end{array}$ & $\begin{array}{c}0.1412 \\
(0.0763)\end{array}$ & $\begin{array}{c}0.0461 \\
(0.0400)\end{array}$ \\
\hline$\hat{r}_{0} 39$ & & 0.0138 & & & 0.0052 & & & 0.0080 & \\
\hline$\hat{r}_{140}$ & & 0.0158 & & & 0.0117 & & & 0.0140 & \\
\hline $\begin{array}{c}\sigma_{\varepsilon} \times 10^{3} \\
41\end{array}$ & & 4.0534 & & & 4.0404 & & & 4.0168 & \\
\hline
\end{tabular}


Notes: Figures in parentheses are heteroscedasticity robust standard errors, ${ }^{*}$ and ${ }^{* *}$ denote significant at $5 \%$ and at $1 \%$ respectively; $\sigma_{\varepsilon} 42$ is the standard error of the regression 